\title{
DERECHOS FUNDAMENTALES Y MEDIO AMBIENTE
}

\author{
Lorenzo MARTÍN-RETORTILLO BAQUER
}

CATEDRÁtico de DERECHO AdMINISTRATIVO

UNIVERSIDAD COMPLUTENSE DE MADRID

CONFERENCIA TRANSCRITA

V Seminario Permanente de Profesores del Departamento de Derecho CURSO 2005/2006: «DERECHO Y MEDIO AMBIENTE»

SESIÓN DE CLAUSURA

SALÓN DE GRADOS DEL EDIFICIO QUINTILIANO (UNIVERSIDAD DE LA RIOJA).

LOGROÑO, 4 DE MAYO DE 2006.

Señor Rector Magnífico, señoras y señores, me agrada mucho estar de nuevo en Logroño, adonde voy viniendo reiteradamente, con unos u otros motivos académicos, con el gusto de estar ahora cerca del profesor Fanlo, muy honrado por la ocasión de figurar en el hermoso tríptico del ciclo que se ha celebrado sobre «Derecho y Medio Ambiente» y tener el honor de clausurarlo. Y con ese afán, el gusto de poder acudir, en la medida de mis posibilidades, allí donde haya alguien interesado por los problemas que hoy a todos nos preocupan, desde la idea de que lo universitario, más allá de cifras y estadísticas, se nutre, sobre todo, por la afición de comunicar, de reflexionar, de apoyarnos mutuamente y de transmitir las pequeñas ideas que vamos enhebrando.

Uno de los pilares interesantes de la construcción europea, en lo cultural y en lo jurídico, viene siendo el sistema puesto en marcha cuando, tempranamente, en la terrible crisis espiritual de la postguerra, al final de la Segunda Guerra Mundial, el Consejo de Europa, desde esa patética convocatoria al «nunca más», puso en marcha un texto magnífico, el Convenio Europeo de Derecho Humanos, que se aprobaba el 4 de noviembre de I950, en Roma, llamado por eso también el Convenio de Roma, que tuvo el acierto de erigir en su apoyo un Tribunal, para que garantizara el compromiso de los Estados con los derechos humanos. 
Y la primera Sentencia se produjo el I de julio del año I96I, el caso Lawles c. Irlanda. Trataba el asunto Lawless de la detención de un miembro del IRA, sin ser puesto a disposición judicial: ¡los viejos demonios de la reciente historia europea que, esperemos, se borren pronto para siempre! Pues bien, el próximo I de julio se cumplirán cuarenta y cinco años de aquella primera decisión que un Tribunal Europeo de Derechos Humanos, con el que se habían comprometido los Estados, dictó en aplicación del Convenio. Por tanto, son cuarenta y cinco años marcando criterio, con resultados muy aparatosos y certeros en ocasiones -aunque no todo lo que hace el Tribunal Europeo de Derechos Humanos tenga la misma calidad-, pero expresando siempre una altura y dando testimonio de un sobresaliente nivel, reflejo todo ello de esta vieja Europa de los derechos humanos, de la que debemos ser conscientes y conocedores, tratando de defender tan rico patrimonio.

Desde el momento de la puesta en marcha hasta hoy, forman parte del Consejo de Europa y están sometidos al sistema del Convenio Europeo de Derecho Humanos nada menos que cuarenta y seis Estados, de modo que -después de algunas decisiones polémicas como, por ejemplo, la de admitir en su seno a Rusia-, la jurisdicción de este sistema llega nada menos que hasta Vladivostok, es decir, prácticamente hasta el Pacífico. Nos encontramos así con una jurisprudencia importante y puntual, que periódicamente nos va sorprendiendo y que preside y prima sobre cada uno de los ordenamientos estatales a los que disciplina. Y quiero recalcar este dato porque, usualmente, se habla de la primacía del Derecho Comunitario, pensando en las Instituciones de la Unión Europea, lo cual es un dato obvio y asumido, pero hay que tener en cuenta que esta otra organización europea, centrada en el tema de los derechos humanos -aunque sean muchas otras las funciones del Consejo de Europa, de las que no es cuestión de ocuparse ahora-, también prima porque los Estados se han comprometido a asumir sus exigencias y a respetar sus previsiones. En este punto concreto nos encontramos con el dato sobresaliente de que los Estados se han vinculado a un Convenio, que es garantizado e interpretado por un Tribunal, que va elaborando una jurisprudencia evolutiva que se va poniendo al día periódicamente.

Con gusto vengo estudiando desde hace tiempo la jurisprudencia de este Tribunal Europeo de Derechos Humanos que, habitualmente denominamos Tribunal de Estrasburgo, y me gusta siempre recomendar a los alumnos el conocimiento de sus casos, desde la idea de que el reto de familiarizarnos con lo europeo, se hace de una manera muy adecuada conociendo los asuntos polémicos sobre los que ha tenido que pronunciarse la jurisprudencia, una jurisprudencia que nos pone en evidencia que los Estados europeos se han comprometido con determinados valores que están por encima de unos y otros, valores que, conviene recalcar, a todos se imponen. Estamos habituados a que el poder se considere que es omnipotente, que dispone de todo, que caben rebajas siempre, desde el señuelo del dialogo. Pues bien, no deja de ser reconfortante pensar que hay unos valores que están por encima, que tienen que ser asumidos y sobre los que no se puede disponer.

Se ha celebrado un ciclo sobre «Derecho y Medio Ambiente». Hoy, vamos a ocuparnos del medio ambiente desde la vertiente de los derechos fundamentales, para analizar algunas sentencias y enfrentarnos con casos concretos que son testimonio de una evolución destacada y muy valiosa. La materia del medio ambiente, a veces nos desborda por su inmensidad, por su intensidad: tan diferentes aspectos, tan variados compromisos, tantas cuestiones. Pues bien, permitan que con metodología universitaria que me gusta practicar, me centre en algún aspecto muy concreto pero que creo pedagógico. Se trata de acotar nuestro tema, para centrarnos y seleccionar algo de una evolución jurisprudencial muy positiva, lo que me lleva a recalcar que los juristas sabemos que los instrumentos jurídicos que manejamos, las constituciones, las leyes, los convenios internacionales son fruto de su época y, a veces, están dotados de una rigidez y solemnidad que impide estar poniéndolos al día constantemente. Si no es fácil modificarlos, ¿cómo responden a las circunstancias que día a día van apareciendo?

Redur 4 / 2006 
Me gustaría en este punto destacar que existen distintas vías para tutelar los derechos fundamentales. Es materia que me viene interesando recientemente. El título de mi último libro es, en esta línea, Vías concurrentes para la protección de los derechos fundamentales (Civitas, 2006). Y es que vivimos en un mundo complejo, donde los instrumentos jurídicos no son ni simples ni sencillos: conviven numerosas variantes, en un panorama difícil que a los juristas nos plantea el reto de saber estar a la altura de las circunstancias. Desde esta metodología, aludiré a tres caminos, que predeterminan el universo de los derechos fundamentales. En primer lugar, la vía o camino de la Constitución de cada uno de los Estados. En segundo lugar, referencia también al Derecho comunitario europeo, cada vez más presente. Pero, en tercer lugar, y es lo que quiero recalcar, la presencia indudable del Convenio Europeo de Derechos Humanos, el Convenio de Roma que, como decía, también forma parte de nuestro ordenamiento jurídico.

En primer lugar, la mención a los textos constitucionales. Cuando se hizo en I978 la Constitución Española, en ese momento, muy reciente la Constitución Portuguesa, lo concerniente al medio ambiente era de plena actualidad. Ello hizo que en I978, al codificarse el sistema de derechos fundamentales, dentro del largo Título Primero de la Constitución, se incluyera en el Capítulo Tercero, sobre los principios rectores de la política social y económica, un artículo 45 con el compromiso de los poderes públicos de respetar el medio ambiente. Recalco que se trata de uno de los principios rectores de la política social y económica. No es un derecho fundamental, en el sentido pleno del término, si bien al respecto se ha producido una significativa evolución. En la doctrina, hay autores que reclaman el carácter de derecho fundamental para la protección medioambiental, siendo de destacar así las aportaciones de Fernando López Ramón, de Andrés Betancor, Francisco Velasco, etcétera. Yo creo que, propiamente, no es un derecho fundamental del bloque de los cualificados, aunque tras la intermediación del legislador van a surgir pretensiones jurídicas que pueden ser llevadas ante los tribunales de justicia. Aparece así una vía operativa en el Derecho interno, muy viva, que nos recuerda que uno no puede dormirse en los laureles porque se trata de una materia rica y compleja, en evolución y en tensión, cada vez más presente, pero siempre menesterosa dadas las peculiaridades del mundo en que vivimos. Por tanto, en primera línea, el Derecho constitucional de cada uno de los Estados.

En segundo lugar, conviene reflexionar acerca de que ahora se están cumpliendo veinte años del ingreso de España en lo que entonces se llamaba la Comunidad Económica Europea, que hoy es la Unión Europea. Bien, la Unión Europea se caracterizó, inicialmente, por ser una organización para lo económico. Quería ser un mercado común. Sus normas primitivas estaban referidas a las materias concernientes al comercio y, sin embargo, esta organización de tanto peso, ha ido incrementando sus opciones, ha ido especificando sus exigencias, cada vez se ha hecho más presente y así lo concerniente a derechos fundamentales y, en concreto, lo referente al medio ambiente cada vez tiene más peso en el sistema comunitario europeo. Es una fortuna para nosotros, los pasos que han podido darse desde la pertenencia de España a la Unión Europea, dado que ésta ha apostado fuerte por el medio ambiente. Permitan que aluda a una serie de tomas de postura inequívocas. Por ejemplo, cuando el artículo tercero del Tratado Constitutivo de la Comunidad Europea (TCE) -sensible a las innovaciones introducidas por el Tratado de la Unión-, enumera qué es lo que pretende, a qué aspira la Unión Europea, encontramos en la letra 1) que se reclama, «una política en el ámbito del medio ambiente». De modo que, desde el primer momento, hay un compromiso comunitario claro para abordar una política en el ámbito del medio ambiente. Y esta proclamación inicial se irá pormenorizando a lo largo del Tratado. Por ejemplo, el artículo sexto, también al inicio, con una fuerza verdaderamente arrolladora, recalca que las exigencias de la protección del medio ambiente deberán integrarse en la definición y en la realización de las políticas y acciones de la Comunidad a que se refiere el artículo tercero, en particular, con objeto de fomentar un desarrollo sostenible. Vean ustedes el mandato. La Unión Europea tiene numerosas políticas: agrícola,

Redur 4 / 2006 
industrial, de transportes, etcétera. Pues bien, es en esas políticas, en todas y cada una de ellas, donde hay que integrar las exigencias propias de la defensa del medio ambiente. Va en serio la cosa.

Pero por citar algún dato más del Derecho comunitario, destacaré que cuando se hace el Tratado de Niza, en el año 2000, en la Declaración Novena anexa se recalcará, y leo literalmente, que «las altas partes contratantes -es decir, los Estados- tienen la firme voluntad de velar porque la Unión Europea desempeñe una función impulsora de la protección del medio ambiente, tanto en el Unión como en el plano internacional para perseguir el mismo objetivo a escala mundial. Deberán aprovecharse plenamente todas las posibilidades que ofrece el Tratado con miras al logro de este objetivo, incluido el recurso a incentivos e instrumentos orientados al mercado y destinados a fomentar el desarrollo sostenible». O sea, que se incluye un compromiso para el interior de la Unión Europea, pero es también un compromiso para que, cuando se actúe hacia fuera, en las relaciones con otros Estados, las preocupaciones medioambientales estén presentes y se actúe en consecuencia.

Una nueva referencia que me lleva al Tratado Constitutivo de la Comunidad Europea es para acudir, en concreto, a la Parte Tercera, donde se enumeran las distintas políticas y ahí, Título Decimonoveno referido al Medio Ambiente, nos vamos a encontrar, igualmente, con preocupaciones destacadas como, por ejemplo, la que expresa el artículo I74, donde leemos, entre otras afirmaciones, la siguiente: «La política de la Comunidad en el ámbito del medio ambiente contribuirá a alcanzar los siguientes objetivos: la conservación, la protección y la mejora de la calidad del medio ambiente; la protección de la salud de las personas; la utilización prudente y racional de los recursos naturales; el fomento de medidas de escala internacional destinadas a hacer frente a los problemas regionales o mundiales del medio ambiente». Y luego, el apartado segundo de este artículo I74, en términos precisos y que realmente deberían estar grabados en piedra en todas las Facultades Universitarias, en todos los centros públicos de enseñanza, señala que «la política de la Comunidad en el ámbito del medio ambiente tendrá como objetivo alcanzar un nivel de protección elevado, teniendo presente la diversidad de situaciones existentes en las distintas regiones. Se basará en los principios de cautela y de acción preventiva; en el principio de corrección de los atentados al medio ambiente, preferentemente en la misma fuente; y en el principio de que quien contamina, paga».

Por tanto, cautelas, predeterminaciones, actuar ex ante, pero, si las previsiones no han dado resultado, deberá quedar muy claro que quien contamina, paga. Estamos por ende ante principios que orientan, de forma indudable, el funcionamiento de la Unión Europea y ya sabemos que en la Unión Europea las reglas, a diferencia de lo que pueda suceder en España, lo que dice el Tratado, se cumple y se exige. Hay medios para ponerlos en marcha. Existen las denuncias de los ciudadanos y existe la posible condena del Tribunal. Se trata de conseguir fórmulas operativas.

Un paso más en este sentido: en el año 2000, en el famoso semestre francés, justo cuando ardían los fastos de las celebraciones de final-principio de siglo y de milenio, se quiso hacer una Declaración de Derechos a la altura de nuestro tiempo, la Carta de Derechos Fundamentales de la Unión Europea, a la que se llevó, artículo 37, un precepto claro que es la expresión de este compromiso. La Carta fue aprobada por los Órganos cualificados de la Unión, aunque quedaba la duda de qué sucedería desde el punto de vista de su aplicabilidad jurídica. Y cuando apareció el Proyecto de Constitución Europea, se produjo la grata noticia de que la Carta de los Derechos Fundamentales de la Unión Europea se convertía en la Parte Segunda del Tratado. De manera que, de aprobarse la Constitución, el texto de la Declaración de Derechos sería Derecho constitucional europeo, formaría parte de la estructura jurídica fundamental de la Unión. ¿Qué va a suceder con la Constitución? No se puede avanzar nada Hoy vivimos en un momento de impasse y no es

Redur 4 / 2006 
posible hacer previsiones, pero nos excita la curiosidad de lo que haya de suceder. De todas maneras, todos sabemos que España se comprometió con este texto, primero por referéndum, después por Ley Orgánica del Parlamento. Y aunque ha habido dos fiascos significativos -el de Francia y el de Holanda-, continúa con a buena marcha el proceso de asunción del texto por parte de nuevos Estados. No se puede saber qué va a suceder, ya digo, pero quiero recalcar que la propia Comisión Europea ha recordado que, como la aprobó y firmó, se siente vinculada por la Carta y, como se siente vinculada por la Carta, cualquier actuación legislativa o administrativa de la Comisión Europea, tiene que superar el baremo y el contraste de adecuación a las exigencias de la Carta. Muy frecuentemente, y con cierta frivolidad, se dice «estamos ante un texto brillante, pero que no es operativo, que no tiene valor jurídico». En efecto no tiene valor jurídico pleno, en cuanto que nunca fue promulgado como tal. Pero los Órganos comunitarios se consideran vinculados por él. Por ejemplo, cuando España es denunciada por lo que sucede con el urbanismo en el caso de la Comunidad Autónoma Valenciana, como ha recordado recientemente Omar Bouazz, resulta que uno de los textos que se ha puesto en aplicación es el compromiso con la Carta a este respecto. Y en efecto el precepto, cuyo contenido no he señalado todavía, -artículo 37 en la Carta, que en la Constitución pasaría a ser el artículo I-97-, recalca, expresando o codificando lo que he dicho anteriormente, que «en las políticas de la Unión se integrarán y garantizarán, conforme al principio de desarrollo sostenible, un nivel elevado de protección del medio ambiente y la mejora de su calidad». No se puede concretar más pero sí que nos encontramos con esta responsabilidad de un nivel de protección del medio ambiente que sea un nivel elevado con el compromiso además de la mejora de su calidad. No cabe duda, por tanto, de que estamos ante algo que tiene importancia decisiva en la Comunidad Europea, que predetermina tantas de las actuaciones de los Estados.

Y hay una tercera línea, una tercera vía, que conviene tener en cuenta desde el punto de vista de la protección y de la defensa de los derechos fundamentales. Volvemos a la «declaración de derechos» que fue aprobada por el Consejo de Europa el 4 de noviembre de I950, el Convenio de Derechos Humanos. El Consejo de Europa, tempranamente, a la vista del alto contenido de ese gran texto del siglo pasado, la Declaración Universal de Derecho Humanos, que hicieron las Naciones Unidas en París, en I948, decide elaborar un sistema para hacer operativa esa Declaración Universal en el ámbito regional europeo. Y es así como entra en lid este Convenio que pone en marcha el sistema del Tribunal de Estrasburgo. Pero, como decía antes, cada texto, cada constitución, cada tratado es hijo de su tiempo. Cada uno refleja las aspiraciones y los problemas de su momento concreto y específico. Hoy sigue teniendo una fuerza destacada este texto que se elaboró en Roma en I950.

¿Y cuáles eran las preocupaciones que estaban en la mente de los europeos en aquel momento concreto y específico? Piensen, media Europa derruida, casas, ciudades, terrenos asolados. Pero también las personas, el vacío, la ausencia de tantos muertos, tantos ciudadanos con las heridas de guerra. ¿Qué es lo que se lleva a este texto de I950? Pues bien, puede parecer sorprendente, hoy cuesta explicárselo a los alumnos, pero en este texto de I950, como del resto, en la Declaración Universal de Derechos Humanos de 1948, nada se dice acerca del medio ambiente. Eran otros los problemas y eran otras las preocupaciones. Lo medioambiental tardaría en llegar. Cierto que el sistema de derechos humanos de Estrasburgo no es un sistema cerrado, no es algo conseguido de una vez por todas, sino que es una fórmula abierta y dinámica que se va ampliando a través de protocolos adicionales. Así, el Convenio de Roma de I950 se completa periódicamente y se hacen nuevos protocolos para incluir otros valores que se suman como derechos fundamentales protegibles. ¿No sería posible incluir el medio ambiente en una de estas declaraciones adicionales, en uno de estos protocolos que se superponen? Se ha intentado, pero aparecen ingentes dificultades. Por de pronto si, inicialmente, integraban el Consejo de Europa los países del núcleo de la vieja Europa, téngase en cuenta que hoy lo integran cuarenta y seis partes. Quiere decir que, en las formas de actuar internacional, tienen que 
ponerse de acuerdo cuarenta y seis Estados. Igualmente, hay que considerar que se puede hablar genéricamente del medio ambiente, como hace el artículo 45 de la Constitución Española. Y es una realidad. Pero también es cierto que todos sabemos que si nos detenemos y profundizamos un poco, el medio ambiente se desdobla en multitud de variantes y contenidos.

Les contaré una anécdota. Soy buen amigo del profesor Martín Mateo que es uno de los pioneros en el estudio de lo medioambiental, y me acuerdo que, una vez, le decía: «bueno, tú diriges tesis con las que uno se encuentra mire donde mire. Porque si mira hacia el aire, el Derecho medioambiental del aire y de la atmósfera o de la luminosidad o de los astros. Si uno mira hacia el mar, el Derecho medioambiental del mar. Si uno mira hacia las aguas, el contenido de los posibles residuos que se echan a las aguas. Si uno mira a la tierra, si uno mira al subsuelo, etcétera». Todos sabemos que la expresión medio ambiente sirve para entendernos pero que, a la hora de la verdad, hay que tener en cuenta numerosas magnitudes concretas y específicas, cada una con sus cifras y niveles, de forma que hay que predeterminar topes, límites, contenidos, numéricamente expresados, con su rigidez inherente: tal grado de acidez, tales contenidos en el agua, tantos decibelios, etcétera. Lo cual es una complicación añadida a la hora de entenderse, de resolver y de dar solución a los problemas.

Con otra particularidad que me gusta también destacar. Hay derechos fundamentales que, diríamos, no cuestan nada. Reconocer una libertad para que actúe la sociedad, en principio, al Estado no le cuesta nada. Pero sabemos que hay derechos fundamentales, como el del medio ambiente, que implican un coste elevado. La sociedad que se compromete con el medio ambiente asume que tiene que dedicar cuantiosas sumas y muy importantes partidas para funcionar de una forma adecuada y correcta, lo cual hace que los Estados se lo piensen, no tengan todos las mismas disponibilidades ni la misma voluntad (estas ideas las he desarrollado en mi comentario Lo medioambiental y la calidad de vida junto a la necesidad de dar cumplimiento a las sentencias, en el $\mathrm{n}^{\circ}$ I25 de la Revista Española de Derecho Administrativo).

E incluso, una última reflexión desde esta perspectiva. Tengamos en cuenta que no pocos Estados de este número de cuarenta y seis que integran esta Comunidad que rige el Convenio Europeo, son países que provienen de la Europa del Este. Y ahí, una de las constataciones tristes que hemos podido hacer es la de que en aquel universo lo medioambiental o no se tenía en cuenta o pesaba poco. O había poco dinero, o no había voluntad, había que atender a otras necesidades y, de hecho, lo medioambiental, resultó un desastre, al menos desde el punto de vista de nuestras actuales exigencias, lo que implica, como saben, que, cuando estos países van ingresando en la otra Comunidad, en la Unión Europea, haya que prever largos periodos para que la adaptación a las exigencias del medio ambiente puedan ser asumidas.

¿Qué representa, qué significa todo esto? Todo esto significa que la situación no es ni fácil ni sencilla. Con frecuencia los alumnos me preguntan por qué no se hace un protocolo adicional sobre el medio ambiente. Se ha intentado, como dije, pero es bien difícil hacer un protocolo adicional sobre el medio ambiente por el conjunto de razones que acabo de exponer, contando con el punto de partida de la rigidez y de la dificultad de poner de acuerdo a tan diversas partes. $\mathrm{Y}$, sin embargo, el sistema de Estrasburgo funciona y es un sistema vivo. El hecho de que no se haya logrado introducir una afirmación clara a favor del medio ambiente, no implica que no haya podido entrar la preocupación medioambiental en tal sistema jurídico.

Tal es el objeto central de mi intervención de esta tarde. Se trata de reflexionar sobre un conjunto de sentencias, testimonio de que, aunque el medio ambiente no ha entrado en el Convenio Europeo de forma expresa, el Tribunal sí es sensible al medio 
ambiente -y mucho- y ello se va reflejando en estos casos, a través de lo que me gusta denominar la «defensa cruzada de derechos». No hay un título claro, no se puede alegar infracción del medio ambiente. Pero a través de otros derechos que sí que están garantizados en esta Declaración se va entrando a defender lo medioambiental. Estamos ante una opción jurídica sobresaliente sobre la que quiero llamar especialmente su atención, fenómeno que se activará a través de diversas fórmulas y sacando fuerza de diversos fundamentos. Por ejemplo, el Protocolo Adicional Uno, artículo primero, protege el derecho de propiedad. Pues bien, encontramos cómo, defendiéndose el derecho de propiedad, puede llegarse a una defensa de lo medioambiental. En otras ocasiones es a través del derecho a la justicia, que marca el artículo sexto. Es muy aparatoso, también, lo que ha sucedido con el artículo 8, sobre el derecho a la intimidad o el derecho al domicilio, que ha dado lugar casos muy espectaculares, a alguno de los cuales aludiré enseguida. Desde la defensa de la intimidad de los ciudadanos o de su domicilio, afloran sentencias que son un claro apoyo en defensa de opciones medioambientales. En ocasiones, será la libertad de expresión la que sirva de palanca para garantizar el medio ambiente. Otras veces, a través de la defensa del derecho de asociación: amparando el contenido del derecho de asociación, se protege el medio ambiente. O incluso, por dar una última muestra, no exhaustiva, al proteger la no discriminación o el derecho a la igualdad, nos encontraremos con que se hace una defensa clara de lo medioambiental. Arrancando de un aparente vacío, resulta muy espectacular constatar cómo la defensa de lo medioambiental va penetrando a través de la metodología de la defensa cruzada de los derechos, que permite que poco a poco, se afiance de forma insistente.

Lo decía en términos tajantes uno de los más acreditados jueces de Estrasburgo, el juez francés Jean-Paul Costa, en una sentencia memorable, el caso Hatton $I$, que es una decisión del 2 de octubre de 200I. Aparecía el problema de en qué medida los ruidos nocturnos del aeropuerto de Heathrow (Londres) perturbaban de tal manera la vida de los ciudadanos que la contaminación acústica se consideraba una intromisión en el propio domicilio. Un sentencia importante y polémica, de la que se desdeciría el propio Tribunal al poco tiempo, pero que, entonces, marcó un hito señalado. Y decía el juez Costa en el voto particular que formulaba a esta sentencia: «Por lo tanto -leo literalmente- me parece que, teniendo en cuenta la jurisprudencia del Tribunal sobre el derecho a un medio ambiente saludable -véase, por ejemplo, la Sentencia López Ostra contra España de 9 de diciembre de I994-, el mantener los vuelos nocturnos en ese nivel, significaría que los demandantes tendrían que pagar un precio demasiado alto por el bienestar económico cuyo beneficio real, además, no se desprende de los hechos del caso, a menos que, por supuesto, se considere que la jurisprudencia va demasiado lejos y sobreprotege el derecho de una persona a un medio saludable. Yo no lo creo así. Desde comienzos de los años setenta el mundo ha ido tomando conciencia progresivamente de la importancia de las cuestiones medioambientales y su influjo sobre la vida de las personas. La jurisprudencia del Tribunal, además, no ha estado sola en el desarrollo de estas líneas. Por ejemplo, el artículo 37 de la Carta de Derechos Fundamentales de la Unión Europea está dedicado a la protección del medio ambiente. Sería deplorable que los esfuerzos constructivos del Tribunal sufrieran un retroceso. Es por lo que, finalmente, he suscrito en lo principal el razonamiento de la mayoría de mis colegas y totalmente su conclusión».

El razonamiento resulta expresivo, y a la par que se debate entre las dudas, es testimonio de la atracción que ha experimentado el Tribunal y que se refleja en su jurisprudencia. No deja de ser curioso que han sido numerosas las sentencias que tienen que ver con el ruido de los aeropuertos. La primera que menciono, la Powel y Rayner contra Inglaterra de I990, tenía que ver directamente con los ruidos del aeropuerto de Heathrow. En aquella ocasión, la sentencia, aún sin estimar el recurso, es ya muy importante como tal, en cuanto reconoce y marca unas exigencias. Se constata que se han tomado numerosas medidas rigurosas para atenuar el volumen de los ruidos. Destaco la constatación. Hay quienes no hacen nada contra el ruido, tantos partidarios como hay de la política del 
avestruz, de esconder la cabeza ante los problemas. En Heathrow se habían adoptado soluciones enérgicas. Lo que justificó que se buscara una salida. El artículo 8 del Convenio de Roma protege la intimidad y el domicilio, si bien el apartado segundo admite excepcionalmente determinadas restricciones. Pues bien, entre estas restricciones, se señala que si la ley lo predetermina, si es proporcional, pueda excepcionarse el derecho en aras a la protección del bienestar económico del país. Y en este caso concreto, la sentencia Powel y Rayner constata que, a la vista del número de medidas que se han tomado, prevalece el interés económico y, por consiguiente, cabe admitir algunas restricciones en el disfrute del derecho, por lo que Inglaterra no habría infringido su obligación de garantizar el derecho a la intimidad.

Pero en el caso Hatton I contra Inglaterra, que es la sentencia de cuyo voto particular me hacia eco hace un momento, se cambia de criterio. El problema era sobre todo, el de los ruidos nocturnos de Heathrow. A la vista de la incidencia de los ruidos nocturnos que se producen en el aeropuerto, en esta primera Sentencia que, repito, luego sería modificada, se produce la condena de Inglaterra: Inglaterra -se dice- al autorizar que el aeropuerto funcione de noche con tal intensidad, no respeta las garantías del derecho a la protección del domicilio, por lo que Inglaterra ha infringido el Convenio. Tal es el punto de partida que marca esta Sentencia del año 200I, tan notable.

El problema fue que la Sentencia sería recurrida. El sistema de Estrasburgo prevé, en casos excepcionales, una segunda opción a través del correspondiente recurso. La sentencia de Sala fue deferida a la Gran Sala y, dos años después, en 2003, la mayoría de jueces entendieron que, a la vista de las circunstancias, no se podía entender que Inglaterra hubiera actuado incorrectamente, no había habido intromisión ilegítima en el domicilio. Aunque es verdad que se condenó a Inglaterra porque no ofrecía las garantías de un recurso efectivo. El debate ha seguido vivo, como se ve, y está claro que preocupa el medio ambiente sonoro.

Otro ejemplo: en España, produjo una enorme sorpresa un caso que, seguramente, todos ustedes conocen por lo que no hablaré mucho. Es el asunto que había suscitado una señora de Lorca, en Murcia, doña Gregoria López Ostra. Es la sentencia de 9 de diciembre del año 1994, López Ostra contra España, que marcó huella. Resulta que en el municipio murciano de Lorca se había producido una instalación de depuración de aguas y residuos químicos que perturbaba de un modo notable el ambiente y producía -como se dice en la sentencia- olores nauseabundos a «huevos podridos», De una manera inesperada, casi diríamos que sonó la flauta por casualidad, el Tribunal fue sensible a estas preocupaciones y problemas, culminando una larga batalla legal, puesto que la recurrente había puesto en marcha la vía penal, la vía de lo contencioso-administrativo ordinaria y la de lo contencioso de protección de los derechos fundamentales. El Tribunal de Estrasburgo entendió que los olores nauseabundos que se producían, implicaban una intromisión injustificable en el domicilio, incompatible con la garantía del respeto a la intimidad que consagra el Convenio. España sería condenada, pero lo relevante es que se marcaba una línea de actuación, ciertamente exigente. Caso que nos suscita, además, otra reflexión que conviene tener en cuenta en un sistema estatal complejo o integrado como es España: quien comparece, quien es parte en estos mecanismos internacionales, es España como Estado o, diríamos, el Reino de España: a consecuencia de la actuación incorrecta o de la negligencia de un ayuntamiento concreto, quien va a ser condenado va a ser el Reino de España que, en definitiva, es quien internacionalmente tiene que dar la cara. Desde el punto de vista de la defensa de lo ambiental, se trata de un paso muy destacado, que se sostiene en la protección del derecho a la intimidad. No me detengo porque creo que es un asunto suficientemente conocido.

Sí que quiero insistir, en cambio, en otra Sentencia, mucho más reciente, que también ha representado un serio aldabonazo, y que tiene que ver con esas ideas de las que

Redur 4 / 2006 
hablaba el profesor Antonio Fanlo al hacer la presentación tan amable que mucho le agradezco: el problema del ruido que, como ustedes saben -y ojalá no lo hayan sufrido en carne viva- es un problema candente en la España de nuestros días. Además uno de esos problemas que nos deja un poco impresionados, viendo cómo los políticos habrán mirado al oráculo, el oráculo les habrá dicho que esto no trae votos, o que no rinde, y han decretado la más absoluta pasividad, pase lo que pase, arda Troya o estén sin dormir los ciudadanos en unos y otros lugares.

Pues bien, el asunto nos sitúa ante el caso de una profesora de Instituto de Valencia, doña Pilar Moreno Gómez que vive en el centro de la ciudad, en una de esas grandes aportaciones españolas a la cultura urbanística, lo que se llama una «zona de copas» -o una «zona de la movida» o como ustedes quieran denominarla-, donde, a cualquier hora del día y de la noche, el pub que está en el bajo -pero también los de enfrente, los de más allá y los del otro lado-, producen ruidos incesantes, que no hay manera de atajar. Denuncias y más denuncias. El Ayuntamiento hace como que hace, pero no hace. Nada se cierra, a nadie se sanciona. Todo sigue igual. Y un buen día, doña Pilar Moreno Gómez decide poner una ventana doble para aislar, y va al Ayuntamiento con la pretensión de que le abonen la factura, solicitando también una pequeña indemnización por los perjuicios sufridos: sus insomnios y desasosiegos. El Ayuntamiento de Valencia, no atiende la solicitud. Es interesante notar la existencia de un precedente, pues una sentencia de la Sala de lo contencioso-administrativo de Valencia había reconocido, años antes, el derecho a indemnización en un supuesto del todo similar. Pero el Ayuntamiento de Valencia, insisto, lo toma olímpicamente y rechaza la indemnización. Doña Pilar recurre en vía contencioso-administrativa y la Sala rechazará el recurso, desde una línea de argumentación impecable: se ha solicitado una indemnización por daños, y lo primero que había que haber cuidado era aportar la prueba de los daños, cosa que no se hizo.

De esta manera, el asunto llega por vía de amparo al Tribunal Constitucional donde había una cierta sensibilidad ante la materia (muy interesado, al parecer, por el tema, el profesor Jiménez de Parga, magistrado a la sazón, y que sería ponente de la sentencia). De hecho, la tramitación del asunto depara una serie de datos notables: por ejemplo, los amparos normalmente son asunto de Sala pero éste se aboca al Pleno. Como regla, en el Tribunal no hay vista y, en este caso concreto, sí la hubo. Yo mismo, acudí interesado por el tema, y aparte de seguir las intervenciones, pude apreciar la cohorte de fotógrafos, periodistas y televisiones presentes en la Sala. Incluso el representante del Ministerio Fiscal se mostró partidario de que se otorgara el amparo, teniendo en cuenta que, como saben, en este tipo de procesos actúa el Ministerio Fiscal. Y el Tribunal Constitucional, al enfrentarse con el asunto, se encontró con que, desde un punto de vista procesal, estaba muy mal planteado el problema de la indemnización, el problema de la prueba era difícilmente solventable, seguramente, incluso, debería haber sido inadmitido. Ello determinó que la sentencia del Constitucional fuera de sentido denegatorio y se rechazara el recurso.

Pero, no obstante, la sentencia, que es la II9/200I, de 24 de mayo, resulta muy relevante porque incorpora un conjunto de declaraciones decisivas desde el punto de vista de lo que significa el ruido: el ruido grave -se viene a decir- puede, en efecto, tener que ver con el derecho a la intimidad y con el derecho a la protección del domicilio que, en el ámbito español garantiza el artículo i8 de la Constitución, lo que, en efecto, a mí personalmente me hizo muy feliz pues, como decía el Profesor Fanlo, desde hace años me había dado cuenta de la relación del ruido con la protección del domicilio. La defensa del domicilio históricamente estaba pensada, y es lógico, para cuando entraban los agentes o malhechores. La primera representación que históricamente haríamos, era contra la intromisión de personas ajenas, ya los agentes públicos, ya los ladrones. Pero en la vida moderna, en el domicilio penetran no sólo personas ajenas: un olor o un ruido es una modalidad que, sin duda, incide con intensidad en la vida y en la intimidad. Y la sentencia 
II9 es clarificadora porque, sin perjuicio de reconocer que no hay prueba, deja bien sentado que el ruido afecta decididamente al derecho a la intimidad.

De modo que, rechazo del Tribunal Constitucional. Lo que pasa es que la señora no se cansó y llegó a Estrasburgo. En el sistema del Convenio Europeo de Derechos Humanos hay un precepto, el artículo 8 que he citado, que es equivalente al artículo i8 de la Constitución Española: derecho a la intimidad, protección de la vida privada, protección del domicilio. Se va a dar pié así a sentencia relevante del Tribunal Europeo de Derechos Humanos. Una sentencia relativamente escueta y para cuya comprensión hay que pensar que se ha tenido que producir una mutación procesal: el asunto punto de partida era pedir una indemnización por daños al Ayuntamiento, pero hábilmente en Estrasburgo se platea alegando que se trata de una infracción del derecho a la intimidad y del derecho al domicilio. El Tribunal constata que era cierto el volumen de ruidos en ese domicilio y, a partir de ahí va a hacer una serie de afirmaciones importantes. Recalcará de forma decidida una de sus frases o afirmaciones preferidas: «los derechos que garantiza el Convenio no son meras declaraciones utópicas e ilusorias sino que tienen que convertirse en realidades efectivas», es decir, se trata de garantizar algo para que sea eficaz y real. Se conviene que resulta cierto que el Ayuntamiento de Valencia, no es el que ha causado los ruidos, no es una acción directamente imputable a los poderes públicos. Pero la filosofía del caso consiste en que el Estado responde de que se garantice el derecho a la intimidad, por activa o por pasiva, lo que quiere decir que tiene que vigilar y defender, tiene que controlar, y tiene que estar presente frente a las intromisiones y ataques que se produzcan. La constatación de la Sentencia será terminante en el sentido de que el Estado no ha estado a la altura de sus exigencias: el Estado no ha garantizado que se produjera una defensa real y efectiva. En consecuencia, se condenará a España diciendo que ha incumplido sus exigencias internacionales de garantizar el derecho a la intimidad y al respeto del domicilio. Y de paso, se condena al Estado Español a que indemnice a la reclamante pagándole una cantidad que significativamente se corresponde con aquella factura por poner la doble ventana en su domicilio, más esa pequeña cantidad como daños morales que había viniendo auspiciando desde el inicio. Por todo ello pienso, en efecto, que el caso Moreno Gómez contra España, del II de noviembre de 2004, no sólo es una victoria para la recurrente, sino que está llamado a tener enorme trascendencia en España.

Y aquí, la pregunta que surge siempre, la pregunta que a uno le plantean: «Bueno, ¿Y esto para qué sirve? ¿Es esto eficaz? ¿Es esto real? Este Tribunal que está allá lejos y hace este tipo de declaraciones, sí, le ha dicho al Estado Español que no ha respetado sus compromisos, y esto ¿qué eficacia tiene? ». Bien, por de pronto, el Estado Español tiene que indemnizar. De nuevo lo que antes decía, en un Estado integrado, al Reino de España, es decir, de nuestro bolsillo nos van a sacar equis céntimos porque el Ayuntamiento concreto no ha llevado a cabo las actuaciones que tenía que cumplir, lo cual, por otra parte, hace pensar que alguna supervisión tendría que haber. Pero, por otro lado, aún tratándose de un asunto concreto, cualquier abogado y cualquier jurista sabe que, de producirse una situación similar, la reacción será la misma. Cualquiera sabe que el Tribunal le dará la razón de repetirse el supuesto.

Es verdad que al ciudadano le espera un camino judicial complejo y enrevesado de seguir, pero se están marcando unos estándares exigibles. Y recordarán cómo hace sólo un par de meses se ha producido un cierto alboroto a consecuencia de residenciarse los problemas del ruido ante la jurisdicción penal. En efecto, en muy pocas semanas -antes había habido un caso en Palencia-, pero en muy pocas semanas, en Zaragoza primero -y de forma tajante, porque ahí la situación del ruido se había deteriorado sobremanera-, Barcelona después, inmediatamente Jaén, ofrecen sentencias penales condenando penalmente a empresarios responsables de locales de ocio que no habían tenido en cuenta las exigencias de respeto a los ciudadanos. Alguna de las sentencias contenía incluso una dura crítica a la autoridad municipal por su dejadez.

Redur 4 / 2006 
A lo que iba: he de recalcar que esta línea jurisprudencial -y otras sentencias similares: en Zaragoza, hubo al mismo tiempo una sentencia contencioso-administrativa marcando una importante responsabilidad para el Ayuntamiento- halla apoyo inmejorable en la sentencia de Estrasburgo señalada. Decisiones como ésta alientan la sensibilidad de nuestros jueces, no en balde las decisiones de Estrasburgo sirven de canon interpretativo a nuestros Tribunales. Es decir, que la jurisprudencia de Estrasburgo se impone al sistema jurídico español: los estándares que marca son también de aplicación en nuestro sistema y deben ser tenidos en cuenta sin excusas. A través del derecho a la intimidad del artículo 8 se organiza esta vía cruzada de derechos, tan útil para proteger lo medioambiental.

Permitan que me refiera a otra sentencia muy reciente, a la que yo mismo he dedicado un comentario que está a punto de aparecer en la Revista Española de Derecho Administrativo. Una decisión que concierne ahora a la isla de Malta, el caso Saliba contra Malta, del 8 de noviembre del año 2005. En ella nos vamos a encontrar con que lo medioambiental entra en la definición de las opciones que el Estado tiene en cuenta a la hora de marcar el estatuto de la propiedad. Yo la he comentado con un cierto interés, a la vista del chaparrón que está cayendo en España, en relación con lo urbanístico, el frecuente desconcierto, el abuso en la edificación, cuando no las irregularidades sin tasa. Tengamos en cuenta que la propiedad está protegida en el sistema de Estrasburgo, en el artículo primero del Protocolo Adicional I, el primero de los que se añadieron, en concreto, a la lista original. Y este artículo primero del Protocolo dice: «Toda persona física y moral tiene derecho al respeto de sus bienes. Nadie podrá ser privado de su propiedad más que por causa de utilidad pública y en las condiciones previstas por la ley y los principios generales del Derecho internacional. Las disposiciones precedentes se entienden sin perjuicio del derecho que tienen los Estados de poner en vigor las leyes que juzguen necesarias para la reglamentación del uso de los bienes de acuerdo con el interés general». Por tanto, protección de la propiedad, pero las leyes reglamentan el uso de los bienes. Una incidencia desproporcionada requeriría expropiación, pero también el Estado es libre para reglamentar la propiedad de alguna manera, para fijar su alcance y contenido.

¿Qué sucedió en este asunto que afectó a la República de Malta? En la finca del Señor Saliba, que estaba en suelo rústico, se había construido sin licencia un almacén: se está ante una edificación ilegal, una edificación sin licencia lo que, en el caso de Malta, está sancionado penalmente. Es una sanción de multa, no es en absoluto una sanción de trascendencia, pero la indisciplina urbanística es objeto de respuesta contundente. Entonces a Saliba le implican penalmente pero resulta que no había sido él quien había edificado, porque él acababa de comprar. Por consiguiente, penalmente, no se dan las circunstancias para que pueda surgir la responsabilidad. Pero el Tribunal, en una nueva actuación, determina que aunque no haya responsabilidad penal, es preciso derribar lo construido dado que es ilegal. El aspecto central se complementa con otras cuestiones conexas: si la norma que preveía el derribo obraba con retroactividad y si la medida era una pena en cuyo caso no podía prevaler el efecto retroactivo. Pero la respuesta del Tribunal va a ser lineal y muy clara pues va a entender que los Estados pueden predeterminar con gran amplitud el régimen de la propiedad. En la determinación del régimen de propiedad cabe perfectamente tener en cuenta la protección del medio ambiente. Si lo que se quiere es que se construya sólo con licencia, desde luego la primera consecuencia, cuando se ha construido ilegalmente, es que las cosas retornen a su estado primitivo. Por consiguiente, parece lógico que lo que se ha edificado de una forma incorrecta sea derribado. El Tribunal recalca que, en efecto, la protección del medio ambiente resulta decisiva en un medio turístico limitado, e incluso, tan poblado como pueda ser una de las islas de Malta; la protección del medio ambiente forma parte indudable de las limitaciones que el Estado puede introducir en el sistema del derecho de propiedad. De modo que la medida cuestionada no es una pena, no es una expropiación, sino que forma parte de la delimitación del derecho de propiedad. Comprenderán que me interesara esta toma de postura, concreta y específica, limitada si quieren, pero muy relevante. El estatuto de la 
propiedad puede asumir el respeto a lo medioambiental si así lo estima el Estado. De este modo encontramos como al diseccionar uno de los derechos garantizados por el sistema del Convenio, aparece de forma inequívoca una rica opción de garantía del medio ambiente.

Les cuento para ir terminando un nuevo asunto interesante, uno más entre los muchos a recordar -me remito a la lista que les he ofrecido y que se recoge en el anexo-, pero no se puede abusar del tiempo ni de la paciencia de los amables oyentes, que me lleva a una materia que, además, sin duda será de mucho interés en esta tierra rica en recursos y afición, me refiero a la caza. Es el caso de la Señora Chassagnou, sentencia de 29 de abril de 1999 contra Francia. Una de las aficiones vivas y reales en la vecina República es la caza. La ley de caza francesa -diré sintetizando mucho-, es una ley que responde a una serie de equilibrios, que trata de encontrar solución a problemas diferentes, que deja de lado a las grandes fincas en que la situación de la caza es menos problemática, pero que obliga, en las pequeñas fincas, a que el propietario que no valle su fundo deba formar parte obligatoriamente de unas asociaciones para la tutela, defensa y vigilancia de la caza y que, desde luego, debe permitir cazar en su terreno. Quien no pone cerca, tiene que integrarse en una determinada asociación, que es la que vigila y controla, impide los abusos, vigila las vedas, persigue a los furtivos, pero la pertenencia a la asociación, junto al derecho a cazar en otros fundos, implica la carga de permitir que se cace, en concreto, en su propiedad.

Resulta que doña Marie-Jeanne Chassagnou participa de una filosofía vital que podría expresarse en términos parecidos a éstos: «yo soy una amante de la vida, soy amante de los animales, a mí me repele la caza y no quiero que se mate a los animales ¿Por qué tiene que obligárseme a formar parte de una asociación? ¿Por qué si no cerco mi finca tiene que obligárseme a dejar cazar en mi finca?». Va así a plantear su oposición en la vía interna, que es rechazada, y llega a Estrasburgo donde el asunto se fundamenta en diversos argumentos. Derecho de propiedad: la propiedad resulta limitada si hay que dejar que entren a cazar los ajenos. Se plantea desde el punto de vista del derecho de asociación, en cuanto se le obliga a formar parte de una determinada asociación. La libertad de asociación que garantiza el artículo undécimo del Convenio de Roma es una libertad para asociarse pero incluye también la vertiente negativa del derecho de asociación: nadie debe ser obligado a asociarse. Se planteará también desde el punto de vista del artículo I4 del Convenio que establece la no discriminación con carácter general, sin que deban pesar diversas circunstancias, como la «fortuna»: los efectos de la Ley no le afectan a quien tiene dinero para cercar su finca; quien no lo tiene queda así discriminado. Pues bien, con apoyo en todas estas argumentaciones, en una razonada y polémica sentencia, el Tribunal de Estrasburgo dará la razón a la recurrente, de modo que también sirven para la defensa cruzada de derechos, el derecho a no ser obligado a asociarse, el derecho de propiedad o el derecho a no ser discriminado por la fortuna. El resultado es un decidido potenciamiento de los valores medioambientales.En resumen, la defensa cruzada de derechos depara estas variantes tan ilustrativas que, además, sumadas todas ellas pesan mucho.

O permitan que aluda, ya muy brevemente, a la Sentencia Vides Aizsardzibas Club contra Letonia de 27 de mayo del año 2004. Aquí se trata de una asociación medioambiental que publica un enérgico artículo en la prensa denunciando que el sistema de dunas de Riga está siendo objeto de ataques por parte de urbanizaciones desaprensivas e ilegales. Por iniciativa de la alcaldesa implicada, la asociación resulta sancionada al estimarse muy duros los términos del artículo. Acuden al Tribunal Europeo de Derechos Humanos y el Tribunal apreciará que, en efecto, hay expresiones duras pero que la libertad de expresión está para se planteen los problemas vivos y reales. La libertad de expresión -es el conocido criterio del Tribunal- está no sólo para lo que agrada sino también para lo que pueda molestar pero resulta importante para la sociedad, concluyéndose que nunca se debió sancionar a esta asociación medioambiental por haber publicado su artículo. Por tanto, también la defensa de la libertad de expresión resulta útil para defender lo medioambiental.

Redur 4 / 2006 
Valgan estos ejemplos, de un acervo jurisprudencial rico y que continuamente nos va deparando nuevos supuestos.

Esto es lo que quería exponerles. Un sistema que debido a la rigidez no ha permitido dar entrada de forma directa al valor medio ambiente, que hoy se considera un derecho fundamental, nos depara esta oportunidad de defensa cruzada a través de la garantía de otros derechos que sí están reconocidos y codificados. Se trata, por consiguiente, de una inteligente e interesante puesta al día a través de la jurisprudencia, que en definitiva incorpora nuevos instrumentos jurídicos que abren caminos y cauces para la defensa de los ciudadanos eso sí, que sepan moverse, dando con estos mecanismos indirectos. Hay que animar por eso a los ciudadanos -a los abogados y, cómo no, a los estudiantes alevines de abogados- para que se familiaricen con la utilización de estos resortes, tan eficaces en ocasiones. Pero téngase en cuenta que no se trata sólo de eso, que es muy importante. Esta jurisprudencia está produciendo automáticamente también otro efecto, el de marcar unos estándares y fijar unas líneas que tienen que ser respetadas por los poderes públicos y por las Administraciones. Sabemos que hay autoridades muy responsables, como hay funcionarios pagados y celosos que tratan a toda costa de que sean respetadas las diversas variantes de protección del medioambiente, pero también nos encontramos con que hay autoridades a las que todo esto les resbala.

No deja de ser significativo que el caso Moreno Gómez contra España al que me he referido, tenga lugar en el municipio del que es alcaldesa la presidenta de la Federación Española de Municipios y Provincias, lo cual no deja de ser un dato significativo. Pues bien, junto a vías concretas para que se proteja a los ciudadanos, se consolidan líneas de respeto que tienen que ser tenidas en cuenta por los poderes públicos. Se asume sin dificultad que el Derecho comunitario europeo prima y se impone, pero es preciso recalcar igualmente que el Derecho del sistema de Estrasburgo, del que forma parte una rica jurisprudencia evolutiva, es una obligación igualmente asumida por España, que también prima, y debe imponerse y que por ende está marcando obligaciones. Aún partiendo de puntos muy concretos, en suma, me ha apetecido mucho comunicarles a ustedes estas reflexiones y entablar esta especie de diálogo que ojalá continuemos ahora por medio del coloquio. Nada más y muchas gracias por su atención. 


\section{ANEXO: SELECCIÓN DE JURISPRUdENCIA DEL TRIBUNAL EUROPEO DE DERECHOS HuMANOS CON CONNOTACIONES MEDIOAMBIENTALES}

(Recuérdese que toda esta jurisprudencia está disponible, íntegra, en francés o en inglés, en Internet, en el espacio del Tribunal, www.echr.coe.int)

Powel y Rayner c. Inglaterra, 2I.II.I990

Zander c.Suecia, 25.XI.I993

López Ostra c. España, 9.XII.I994

Guerra c. Italia, I9.II.1998

Chassagnou c. Francia, 29.IV.I999

Coster [y varias otras de la misma fecha] c. Inglaterra, I8.I.200I

Hatton I c. Inglaterra, 2-X.200I

Hatton II c. Inglaterra, 3.VII.2003

Kyrtatos c. Grecia, 22.V.2003

Ashworth c. Inglaterra [decisión de inadmisión], 20.I.2004

Vides Aizsardzibas Klubs [Club para la Protección del Medio Ambiente] c. Letonia, 27.V.2004

Taskin c. Turquía, Io.XI.2004

Moreno Gómez c. España, II.XI.2004

Öneryildiz c. Turquía, 30.XI.2004

María Isabel Ruano c. España [decisión de inadmisión], 6.IX.2005

Saliba c. Malta, 8.XI.2005

Fadeya c. Rusia, 30.XI.2005

Luginbühl c. Suisa [decisión de inadmisión], I7.I.2006

Athanasiou c. Grecia, 9.II.2006 